\title{
Night blindness and vitamin A deficiency following jejunoileal bypass surgery
}

\author{
PAUl C. ADAms, MD, FRCPC, CHRISTOPHER L. CANNy, MD, FRCSC
}

\begin{abstract}
A 42-year-old man who developed severe night blindness 15 years following jejunoileal bypass surgery for morbid obesity is described. Ophthamological testing, including dark adaptation, electroretinography and serum vitamin A levels, confirmed a diagnosis of vitamin A deficiency. Oral vitamin A 25,000 iu/day for two months resulted in a full recovery of visual deficits. Nutritional vitamin A deficiency is discussed in the context of intestinal bypass surgery. Can J Gastroenterol 1989;3(4):138-140
\end{abstract}

Key Words: Jejunoileal bypass, Vitamin A deficiency

Cécité nocturne et carence en vitamine $\mathrm{A}$, suite à un court-circuit jéjunoiléal

RESUME: On décrit le cas d'un homme de 42 ans chez qui s'est développée une récité nocturne grave, 15 ans après qu'il a subi un court-circuit jéjunoiléal pour le traitement de l'obésité morbide. Les examens ophtalmologiques - adaptation à l'obscurité, électrorétinographie et taux sériques de vitamine $\mathrm{A}$ - ont confirmé le diagnostic de carence en vitamine A. L'administration orale de 25,000 iu/jour de vitamine A pendant deux mois a résulté en la guérison totale de tous les déficits visuels. La carence nutritionnelle de vitamine A est examinée dans le contexte de la chirurgie du court-circuit intestinal.

Department of Gastroenterology and Ophthalmology, University Hospital, University of Western Ontario, London, Ontario

Correspondence and reprints: Dr Paul C. Adams, Room 5-OF 18, University Hospital, PO Box 5339, London, Ontario N6A 5A5. Telephone (519) 663-3513

Received for publication Mav 5, 1989. Accepted June 12, 1989
J

EJUNOILEAL BYPASS SURGERY WASA commonly used surgical procedure in the treatment of morbid obesity in the 1970s. Although the procedure was very successful in facilitating weight loss, the operation fell into disfavour with increasing numbers of reports of side effects such as liver failure, renal calculi, bone disease, skin rashes and nutritional deficiencies $(1,2)$. Subclinical vitamin A deficiency has previously been uncovered in jejunoileal bypass patients who have undergone ophthal. mological testing $(3,4)$ but clinical vitamin A deficiency manifesting as night blindness in this setting is a rare occurrence with only a few cases previously described (5-8).

\section{CASE PRESENTATION}

A 42-year-old man underwent an end-to-side jejunoileal bypass in 1973 for morbid obesity at which time he weighed $207 \mathrm{~kg}$. The patient lost $105 \mathrm{~kg}$ following the procedure. He was rela. 


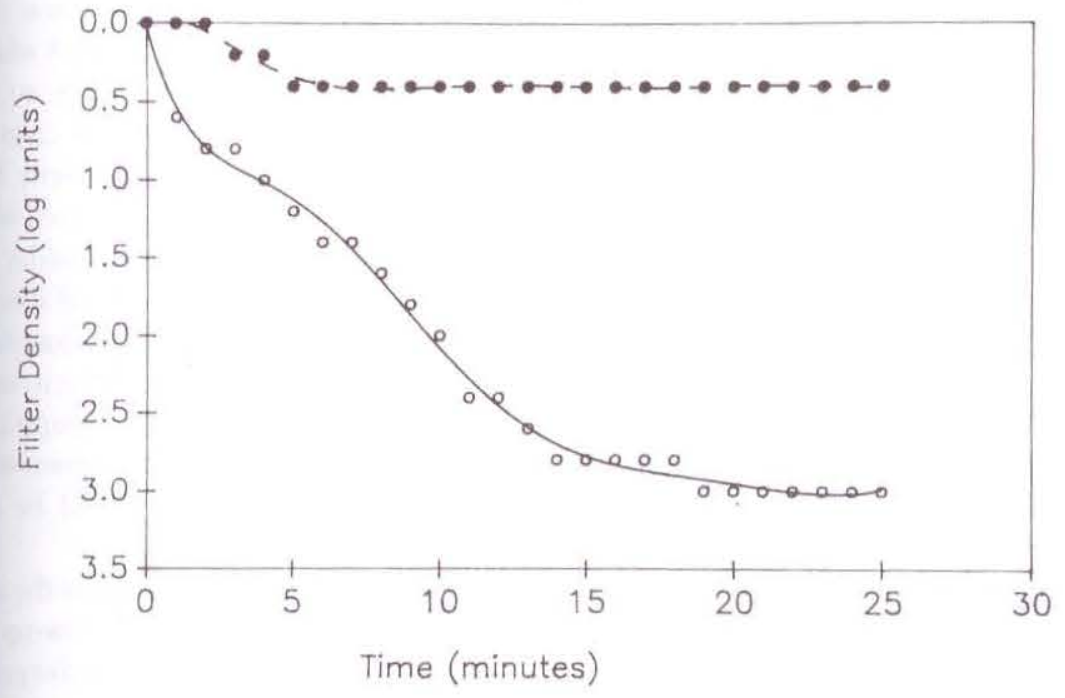

Figure 1) Dark adaptation curves of the left eye using the Friedman central field analyzer before (dosed circles) and after (open circles) vitamin A therapy. A similar dark adaptation pattern was seen in the right eye. The graph describes the relative intensity that is required for a test light to just be seen. Itdemonstrates the change in this relative intensity over time

tively well until 1987 when he developed visual problems, renal calculi, skin rash and paresthesia in his hands and feet. Vitamin B12 deficiency with megaloblastic anemia was documented and treated. The patient continued to have visual problems which were progressive. He complained of great difficulty in driving his car at night and in ambulating around his home in the evening. This progressed to where he could no longer drive at night and he had several falls at home after bumping into objects in his home under low light conditions. Reading ability and concentration had also deteriorated. The patient was investigated for vitamin A deficiency and was treated with oral vitamin A 25,000 iulday. Within two weeks of therapy the patient reported a marked improvement in his night vision and reading ability. Two months after oral therapy was initiated ophthalmological testing was repeated.

Physical examination: Head and neck examination was normal; chest was clear; heart sounds were normal; $a b$. dominal striae were present; there was no hepatosplenomegaly, palmar erythema, ascites or encephalopathy; a papular skin rash was present on the thest and abdomen.
Laboratory examination: Laboratory results were as follows: electrolytes were normal; hemoglobin $147 \mathrm{~g} / \mathrm{L}$; mean corpuscular volume $101 \mathrm{fL}$; serum folate $8.2 \mathrm{nmol} / \mathrm{L}$; albumin $38.2 \mathrm{~g} / \mathrm{L}$; calcium $2.12 \mathrm{mmol} / \mathrm{L}$; urate $383 \mu \mathrm{mol} / \mathrm{L}$; bilirubin $11.2 \mu \mathrm{mol} / \mathrm{L}$; alanine aminotransferase $31 \mathrm{iu} / \mathrm{L}$; aspartate aminotransferase $16 \mathrm{iu} / \mathrm{L}$; alkaline phosphatase $127 \mathrm{iu} / \mathrm{L}$; prothrombin time $11 \mathrm{~s}$; plasma zinc $11.5 \mu \mathrm{mol} / \mathrm{L}$ (normal 10.7 to 22.9 ); serum 25 - hydroxyvitamin D $10 \mathrm{nmol} / \mathrm{L}$ (normal 20 to 80 ); serum vitamin A $0.7 \mu \mathrm{mol} / \mathrm{L}$ (normal 1.2 to 2.8 ). Percutaneous liver biopsy showed moderate macrovesicular fatty change with mild portal and central fibrosis with foci of bridging fibrosis. Computed tomography bone densitometry showed reduced bone mineral content at $131 \mathrm{mg} / \mathrm{mL}$ (normal 180 25 ). Ophthalmological investigation: Ophthalmic assessment in October, 1988 revealed a visual acuity of $6 / 6(20 / 20)$ in the right eye and 6/7.5 (20/25) in the left eye, and early presbyopia. Mild superficial punctate keratitis was present; intraocular pressure was normal. Fundoscopic examination was normal. The visual field (Goldmann perimetry) in each eye showed a mild but definite constriction to all targets tested. Dark adaptation using the Friedmann central field analyzer (Clement Clarke Ltd, London), was markedly abnormal showing an increase in cone threshold and a delay in cone adaptation as well as absent rod adaptation (Figure 1). Electroretinography showed a marked reduction in A- and B-wave amplitudes in scotopic and photopic conditions. Electroretinography in vitamin $\mathrm{A}$ deficiency shows first a disappearance of the A-wave, followed by the B-wave as the deficiency became more severe $(4,9-11)$.

After two months of 25,000 iu/day of vitamin $A$ the visual fields and electroretinogram had returned to normal. Dark adaptation showed a biphasic response with lowered cone threshold and a near normal rod response.

\section{DISCUSSION}

This case illustrates a nutritional vitamin A deficiency manifesting as night blindness which responded to high dose oral vitamin A therapy. The patient developed the clinical signs of vitamin A deficiency 15 years after jejunoileal bypass, presumably as a result of malabsorption of vitamin $\mathrm{A}$. Vitamin A (retinol) is ingested as the ester (dairy products, margarine) or as beta-carotene (vegetables) and is hydrolyzed by specific enzymes prior to absorption. The vitamin is hydrophobic and must be absorbed in mixed micelles into the enterocyte and then transported to the liver via chylomicron remnants. The liver is the major storage site for vitamin A primarily in the fat storing cells or Ito cells. An enterohepatic circulation has been described for vitamin $\mathrm{A}$ and its metabolites but its clinical significance is unknown. Vitamin A leaves the liver bound to retinol binding protein which complexes with transthyretin and in this form vitamin $A$ is delivered to target cells such as the retina which also contains specific cellular retinol bind. ing proteins. Oxidation of retinol results in the production of retinal which is the prosthetic group of all the visual pigments that capture light in the retina. This reaction is dependent on zinc and zinc deficiency has been described to cause functional vitamin $\mathrm{A}$ deficiency, particularly in patients with alcoholic cirrhosis of the liver (12). 
Perlman and colleagues (3), reported a 58-year-old woman who developed reduced visual function 11 years after jejunoileal bypass. The patient improved following reversal of the bypass and parenteral vitamin A. Rod adaptation, sensitivity and electroretinography responses did not return to normal for seven months.

Brown et al (4) described a 33-yearold man who developed night blindness three-and-one-half years following jejunocecostomy. Treatment with oral vitamin A 25,000 iu/day resulted in a dramatic visual improvement in three days and long term follow-up was not reported. Rogers and co-workers (5) searched for deficiencies in fat soluble vitamins in 40 consecutive patients who had undergone jejunoileal bypass from one to 72 months after surgery. Despite an adequate dietary intake of vitamin $\mathrm{A}$ and regular multivitamins functional derangements of retinal adaptation to darkness were discovered in four asymptomatic patients. Three patients were treated with oral vitamin A 25,000 to $65,000 \mathrm{iu} /$ day with normalizatios of function in all three patients.

The present case of vitamin A deficiency probably resulted from a malabsorption of the vitamin from a decreased surface area of available small intestine. The vitamin D deficiency

ACKNOWLEDGEMENTS: The authors acknowledge the assistance of Pauline Randall, James Donaldson and George Kuruvilla.

\section{REFERENCES}

1. Hocking MP, Duerson MC, O'Leary P, Woodward ER. Jejunoileal bypass for morbid obesity. Late follow-up in 100 cases. N Engl J Med 1983;308:995-9.

2. Halverson JD, Scheff RJ, Gentry K, Alpers DH. Long term follow-up of jejunoileal bypass patients. Am J Clin Nutr 1980;33:472-5.

3. Perlman I, Barzilai D, Haim T, Schramek A. Night vision in a case of vitamin A deficiency due to malabsorption. Br J Ophthamol 1983;67:37-42.

4. Brown GC, Felton SM, Benson WE. Reversible night blindness associated and resultant bone demineralization would support a generalized malabsorption of fat soluble vitamins.

Since hepatic dysfunction and cirrhosis can accompany jejunoileal bypass, a decrease in the intraluminal bile salt pool could also contribute to vitamin A malabsorption in some jejunoileal bypass patients. Also, diminished exposure to pancreatic and intestinal enzymes necessary for the metabolism of retinol and beta-carotene may contribute to vitamin A deficiency. Decreased intake of vitamin A can rarely occur in conditions such as anorexia nervosa and alcoholism (13).

The present patient was started on $25,000 \mathrm{iu} /$ day of oral vitamin A because this was the minimum effective dose in two previous reports describing four patients $(4,5)$. The optimal dose and duration of therapy is unknown in this uncommon condition. In this patient, malabsorption of vitamin A is likely to continue unless the bypass procedure is reversed. Since vitamin A is stored in the body, it is possible that oral therapy could be discontinued until vitamin $\mathrm{A}$ stores are depleted again. In the patient described by Perlman et al (3), the dark adaptation continued to improve after the oral vitamin A therapy had been discontinued. Because there is not a widely available test for serum vitamin A levels and repeated dark adaptation

with intestinal bypass surgery. Am J Ophthamol 1980;89:776-9.

5. Rogers EL, Douglass W, Russell RM, Bushman L, Hubbard TB, Iber FI. Deficiency of fat soluble vitamins after jejunoileal bypass surgery for morbid obesity. Am J Clin Nutr 1980;33:120814.

6. Barr DJ, Riley RJ, Greco DJ. Bypass phrynoderma. Vitamin A deficiency associated with bowel-bypass surgery. Arch Dermatol 1984;120:919-21.

7. Wecksler HL. Vitamin A deficiency following small bowel bypass surgery for obesity. Arch Dermatol 1979;115:73-5.

8. Carney EA, Russell RM. Correlation of dark adaptation test results with serum vitamin $\mathrm{A}$ levels in diseased adults. J Nutr 1980;110:552-7.

9. Russell RM, Smith VC, Multack R, Krill AE, Rosenberg IH. Dark adaptation testing for diagnosis of subclinical testing is not practical in many cases the authors have chosen to treat this patient with a dose of vitamin A which was beneficial but unlikely to be hepatotoxic. The majority of cases in which vitamin A hepatotoxicity has been clearly established occurred with doses greater than 40,000 iu/day in patients with presumed normal absorp. tive mechanisms (14). Since jejunoileal bypass surgery is no longer done in most major medical centres, empirical therapy for the uncommon patient with vitamin A deficiency could be individualized.

The present case highlights the importance of long term follow-up of patients who have undergone jejunoileal bypass. Retinal changes may be irreversible after long standing deficiencies $(4,10)$. Serum vitamin A levels may not be an adequate reflection of total body stores and clinical night blindness is a late and uncommon manifestation of vitamin A deficiency. Since vitamin A can be associated with considerable toxicity including hepatic fibrosis, routine administration of high doses of vitamin $A$ is not recom mended. Intestinal bypass patients should be evaluated by an ophthal. mologist for subclinical symptoms and supervised long term therapy with the minimum effective dose should be in stituted.

vitamin A deficiency and evaluation of therapy. Lancet 1973;ii:1161-2.

10. Dowling JE. Night blindness, dark adaptation and the electroretinogram. Am J Ophthamol 1960;50:875-7.

11. Partamian LG, Sidrys LA, Tripathi RC. Iatrogenic night blindness and keratoconjunctival xerosis. N Engl ] Med 1979;301:943-4.

12. Morrison SA, Russell RM, Carney EA Zinc deficiency: A cause of abnormal dark adaptation in cirrhotics. Am J Clin Nutr 1978;21:276-81.

13. Alpers DH. Absorption of vitamins and divalent minerals. In: Sleisenger M, Fordtran J, eds. Gastrointestinal DiseasePathophysiology, Diagnosis, Management, 4th edn. Philadelphia: WB Saunders, 1989:1051-2.

14. Goodman DS. Dietary A and retinoids in health and disease. N Engl J Med 1984;310:1023-7. 


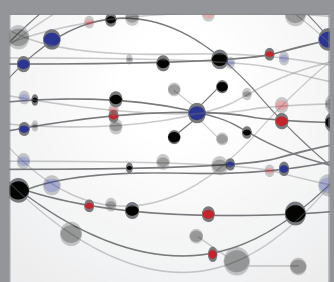

The Scientific World Journal
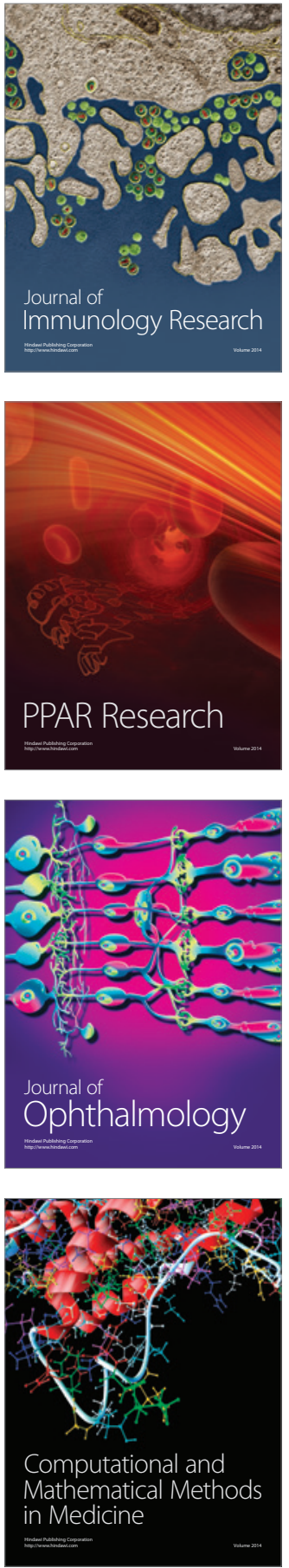

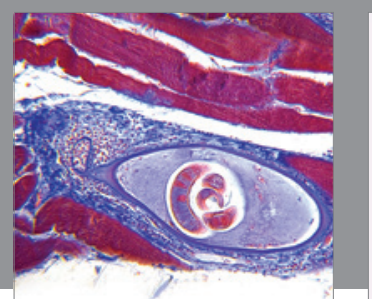

Gastroenterology Research and Practice

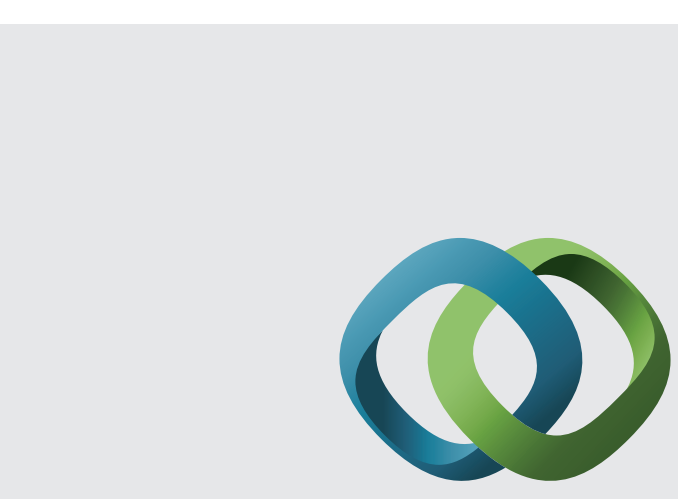

\section{Hindawi}

Submit your manuscripts at

http://www.hindawi.com
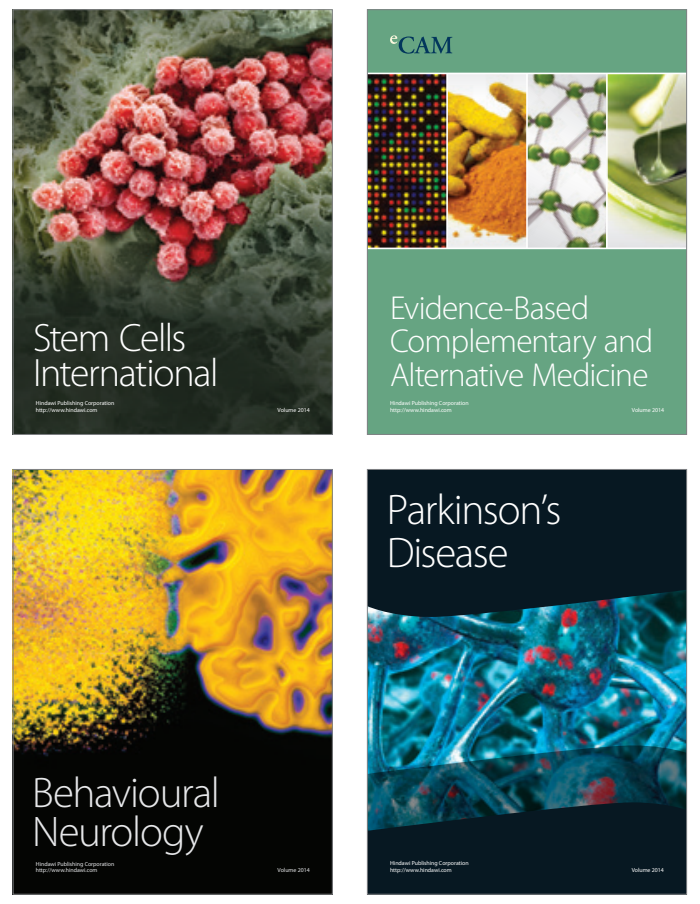
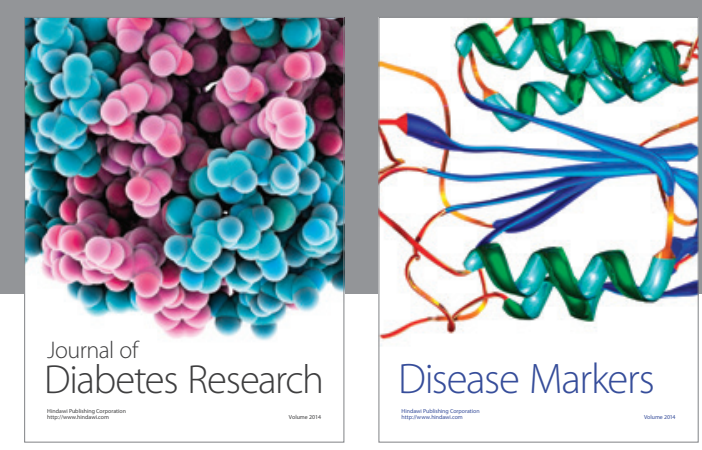

Disease Markers
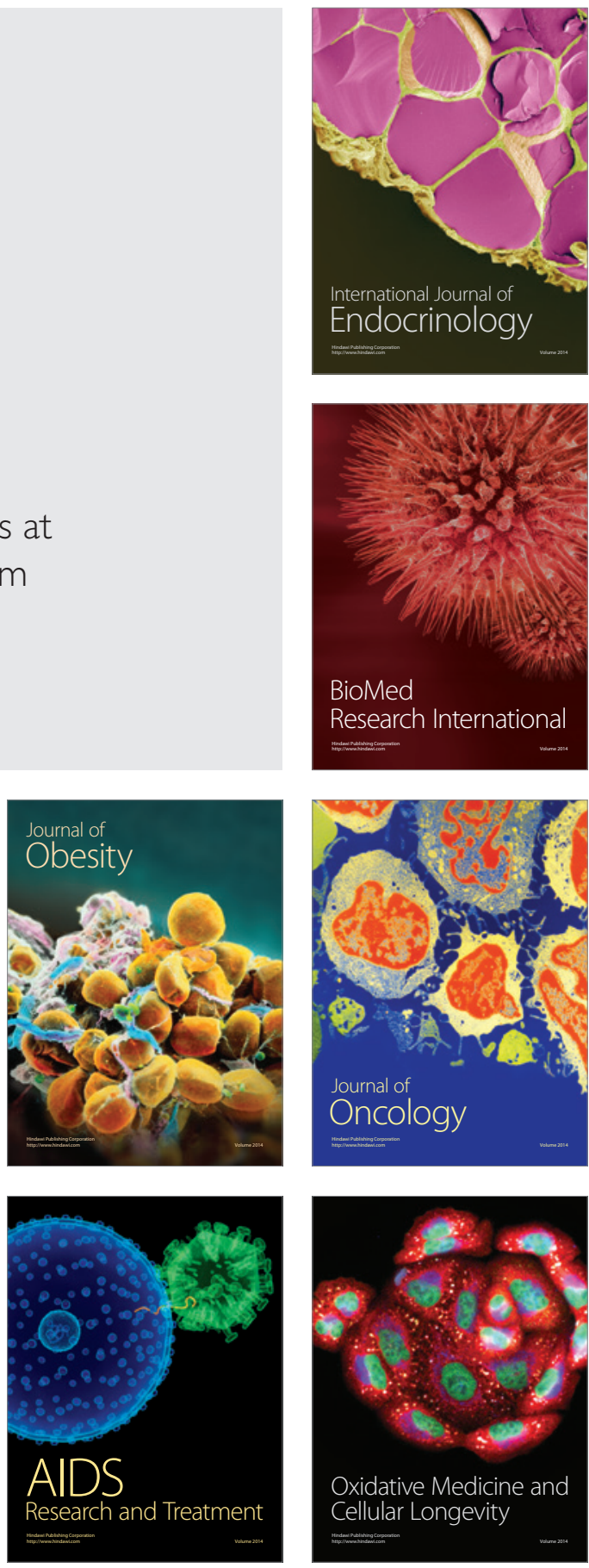